simple matter to introduce some or all of these factors into other schemes around the country. Increasing research productivity might lead to the conclusion that these are important contributory factors.

Queen's Medical Centre

Nottingham NG7 $2 \mathrm{UH}$

Ola Junaid

RACHEl DALY

\section{Trainees' research}

\section{DeAR SIRS}

I read with a growing sense of disquiet Shôn Lewis' paper 'A Prospective Controlled Trial of Trainees' Research' (Psychiatric Bulletin, August 1991, 15, 478-480). What are the ethical implications of using trainces in research without obtaining their prior consent? This is particularly relevant as the consequences of this intervention may have significant positive outcome on their careers. Although there was capacity for ten trainees on the course, eight were selected. In effect two trainees were excluded from a course which improved performance on objective indicators of research activity. Excluding intervention universally accepted as 'of benefit' would not be permitted by an ethical committee looking after the interests of patients; trainees deserve at least the same protection.

Dr Lewis raises the very important question, should a publication be so important in determining career progression? Can psychiatry afford to lose those clinicians who combine empathy, diligence and efficiency but have no desire to play the research game? For make no mistake, it has become a game. Authorship may mean nothing more than performing a handful of mini-mental states or a dozen physical examinations. An uncited publication in an obscure journal may be good for the ego and get you shortlisted, but is there a positive correlation with becoming a successful consultant?

\section{Mapperley Hospital}

O. JUNAID

Nottingham NG3 6AA

\section{DeAr SiRs}

While acknowledging Dr Junaid's concern about ethical issues, I may say I did not worry unduly about this. Perhaps I was wrong, but it could be argued that it would be more unethical not to offer trainees a research course at all, or to engage trainees in a research course which was unevaluated.

Dr Junaid also asks whether publications should be so crucial in deciding a trainee's future career. In my experience, clinicians fall into one of two groups on this issue. Some clinicians think that researchers are better clinicians while others think that researchers are worse clinicians. Although not published in the earlier report, I actually undertook a small subsequent study to try and look at the validity of these assumptions. In opting for candidates with publications on their $\mathbf{C V}$, were appointment committees shortlisting the right people? Following the senior registrar appointment committee referred to in the article, which shortlisted 11 candidates out of 32 and was more likely to shortlist those with a publication, I sent questionnaires to each of the 32 applicants. These were sent one month after the interviews and consisted of eight statements which the trainee was asked to rate his or her agreement, from "strongly disagree" to "strongly agree". The statements were constructed with the aim of reflecting the ability and commitment of the trainee as a future clinician and included items such as "I sometimes find it difficult to get on with other staff members", "I am well organised at work", "I am sure that psychiatry was the right career choice", and so on. Trainees were asked to answer anonymously, although whether or not a questionnaire had been completed by a shortlisted or non-shortlisted trainee was known. After two mailings, 24 of the trainees replied $(75 \%)$. The two groups of those who had been shortlisted $(n=8)$ and those who had not $(n=16)$ were compared on their responses with the hypothesis that the shortlisted group would show evidence of more committed attitude to their chosen clinical career. A distinct difference between groups was shown in the response to one item only: "I enjoy every aspect of clinical work". However, this difference was in the opposite direction to that predicted: 14 of the 16 non-shortlisted trainees agreed mildly or strongly with the statement, compared to just 3 of the 8 shortlisted trainees (Fisher's Exact $P=0.004$ ). Thus, such an item reflects clinical commitment, it seems that the committee might not be succeeding in shortlisting the most worthy candidates; although the proper interpretation of this finding is probably not straightforward.

\section{Charing Cross and Westminster Medical School St Dunstan's Road \\ London W6 8RP}

\section{"Cannabis psychosis"}

\section{DeAr SIRS}

I was intrigued by Dr Thomas' correspondence (Psychiatric Bulletin, August 1991, 15, 504) on "cannabis psychosis". I could not help speculating on the impetus behind his letter. Is there a major drug problem out there on the mean streets of downtown Pontyclun? And if so, how does this impinge on Dr Thomas whose business address is given enigmatically as, merely, Near Pontyclun. While the nosological status of "cannabis psychosis" is unclear 
and deserves more research, I would predict that after a couple of days in our unit in South East London, he would soon run out of inverted commas.

King 's College Hospital and ANTHONY DAVID

Dulwich (North) Hospital

St Francis Road

London SE22 8DF

\section{Dear Sirs}

I agree with Dr David that the nosological status of "cannabis psychosis" is unclear. Psychotic reactions to cannabis are uncommon in Western societies despite the drugs widespread use (ARF, 1981). I am intrigued by the suggestion that the number of cases seen in Camberwell is so overwhelming - perhaps this provides a setting for the research Dr David advocates to clarify the issue. In the meantime the hard-pressed doctors of King's College could perhaps save on the use of inverted commas by applying appropriate ICD or DSM diagnoses.

As for my own interest in the subject, this stems from time spent working with the Mid-Glamorgan Community Drug Team, whose catchment area includes three of the poorest local authority districts in England and Wales and draws clients from socially disadvantaged communities whose streets are as mean as any in South-East London.

Brynffynon Child and Family Therapy Clinic

Huw Thomas

Pontypridd

Mid-Glamorgan CF37 4DD

(Formerly of Hensol Hospital)

\section{Reference}

Addiction Research Foundation (1981) Report of an ARF/WHO scientific meeting on adverse health and behavioural consequences of cannabis use. Toronto.

\section{The portable computer in psychiatry: tips on buying one}

\section{Dear Sirs}

We read with interest $\mathrm{Dr}$ Littlejohns' article (Psychiatric Bulletin, August 1991, 15, 493-495) but were disappointed that no distinction was made between "palm top" (mostly personal organisers the size of a small paperback), "notebook" (usually the size of A4 paper and often weighing less than $10 \mathrm{lbs}$ ) and "laptop" computers (almost anything that can be lugged around in a small bag: some weigh more than "desk top" computers).

Additionally, describing the Cambridge Z88 in such detail, a rather archaic machine by today's standards, does not accurately represent the current trend in portable computers: the user is confined to miniscule memory, truly basic wordprocessing, having to learn "Basic" (a programming language), incompatibility with so-called IBM clones and no practical way of running important software such as statistical packages. The modem set-up is fiddly.

Anyone considering portable computing should think about an IBM compatible "notebook" with a battery life of more than one and a half hours, a well lit screen and preferably an internal modem. Hard disk space would be a bonus and a working memory (loosely termed RAM) of one megabyte is usually adequate. Furthermore, most portable computers nowadays can serve quite adequately as the user's only machine. Toshiba's T1000 range, or the Sanyo MBC-17NB are rather good, and the cost can be kept down by asking for an educational discount which can be as much as $35 \%$ below the list price. Really smart buyers get their goods in the United States and still make a saving after paying their fare and accommodation: a budget of $£ 800$ would not be unrealistic. For those who really need computing, a 286 (a type of micro-processor) based machine is the best choice. Those wishing to use a Graphical Interface such as "Windows" (which makes an IBM based machine run like an Apple Mackintosh) should think hard about a 386SX (another type of micro-processor) machine. In the near future, "notebooks" will have Cellular Telephone communication facilities instead of, or in addition to, a modem fax.

Market leaders in portable computing include Toshiba, Compaq, Dell, Tandon, Zeos, NEC and Viglen: there appears to be a direct correlation between reliability (which is poorer with "notebooks" compared with "desktops") and the buyer should be cautious of very "cheap" products.

We applaud Dr Littlejohns for raising the profile of portable computing in psychiatry.

\section{Warneford Hospital Oxford $O X 37 J X$}

B. A. Johnson

Wycombe General Hospital

L. T. WELLS

High Wycombe, Bucks

\section{DEAR SIRS}

I attempted in this article, to state my personal requirements and show the decision process that produced a best fit solution, for me. It was not my aim to formally review portable computing.

Much computer terminology is sales talk. 'Palmtop' must be a new one, but I understood 'laptop' and 'notebook' to be synonymous, and very recent, terms. Most computers called merely 'portable' as I think Johnson and Wells sought to infer, are often quite big, with a handle on them. I, however, used the word conventionally.

The small memory of the Z88 can now be expanded to $1500 \mathrm{k}$, which is reasonably excessive bearing in 